\title{
A change detection approach to flood mapping in urban areas using TerraSAR-X
}

Article

Accepted Version

Giustarini, L., Hostache, R., Matgen, P., Schumann, G., Bates, P. D. and Mason, D. C. (2013) A change detection approach to flood mapping in urban areas using TerraSAR-X. IEEE Transactions on Geoscience and Remote Sensing, 51 (4). pp. 2417-2430. ISSN 0196-2892 doi: https://doi.org/10.1109/TGRS.2012.2210901 Available at https://centaur.reading.ac.uk/29866/

It is advisable to refer to the publisher's version if you intend to cite from the work. See Guidance on citing.

To link to this article DOI: http://dx.doi.org/10.1109/TGRS.2012.2210901

Publisher: IEEE Geoscience and Remote Sensing Society

All outputs in CentAUR are protected by Intellectual Property Rights law, including copyright law. Copyright and IPR is retained by the creators or other copyright holders. Terms and conditions for use of this material are defined in the End User Agreement.

www.reading.ac.uk/centaur 
Central Archive at the University of Reading

Reading's research outputs online 


\title{
A change detection approach to flood mapping in urban areas using TerraSAR-
} $\mathbf{X}$

Laura Giustarini, Renaud Hostache, Patrick Matgen, Guy Schumann, Paul D. Bates, and David C. Mason

L. Giustarini, R. Hostache and P. Matgen are with the Centre de Recherche Public Gabriel Lippmann, Département Environnement et Agro-biotechnologies, L-4422 Belvaux, Grand-Duchy of Luxembourg (email: giustari@lippmann.lu; hostache@lippmann.lu; matgen@lippmann.lu)

G. Schumann and P. D. Bates are with the School of Geographical Sciences, University of Bristol, BS8 1SS Bristol, U.K. (email: guy.schumann@bristol.ac.uk; paul.bates@bristol.ac.uk)

D. C. Mason is with the Environmental System Science Centre, University of Reading, RG6 6AL Reading, U.K. (email: dcm@ mail.nerc-essc.ac.uk)

\begin{abstract}
Very high-resolution Synthetic Aperture Radar sensors represent an alternative to aerial photography for delineating floods in built-up environments where flood risk is highest. However, even with currently available SAR image resolutions of $3 \mathrm{~m}$ and higher, signal returns from man-made structures hamper the accurate mapping of flooded areas. Enhanced image processing algorithms and a better exploitation of image archives are required to facilitate the use of microwave remote sensing data for monitoring flood dynamics in urban areas. In this study a hybrid methodology combining radiometric thresholding, region growing and change detection is
\end{abstract}


introduced as an approach enabling the automated, objective and reliable flood extent extraction from very high-resolution urban SAR images. The method is based on the calibration of a statistical distribution of "open water" backscatter values inferred from SAR images of floods. SAR images acquired during dry conditions enable the identification of areas i) that are not "visible" to the sensor (i.e. regions affected by 'layover' and 'shadow') and ii) that systematically behave as specular reflectors (e.g. smooth tarmac, permanent water bodies). Change detection with respect to a pre- or post flood reference image thereby reduces over-detection of inundated areas. A case study of the July 2007 Severn River flood (UK) observed by the very high-resolution SAR sensor on board TerraSAR-X as well as airborne photography highlights advantages and limitations of the proposed method. We conclude that even though the fully automated SAR-based flood mapping technique overcomes some limitations of previous methods, further technological and methodological improvements are necessary for SAR-based flood detection in urban areas to match the flood mapping capability of high quality aerial photography.

\section{INTRODUCTION}

The support of remote sensing for mapping changes in water surface extents and elevations has been demonstrated widely (for detailed reviews see [1]-[3]). The success of these research studies together with recent public and political awareness for quantifying global environmental change has led to a significant increase in the number of satellites dedicated to flood monitoring and hydrology in the wider sense. Importantly, flood monitoring from space has the advantage of large area coverage and relatively fast response services (see for example the International Charter' Space 
and Major Disasters' initiated by major space agencies: http://www.disasterscharter.org/).

The vast majority of a flooded area is rural rather than urban and accordingly most literature on remote sensing based flood detection to date has focussed on the rural case. However, it is perhaps more important to detect the urban flooding because of the increased risks and costs associated with it. Flood extent can be detected in rural floods using SARs such as ERS and ASAR, but these have too low a resolution (25 m) to detect flooded streets in urban areas. However, a number of SARs with spatial resolutions as fine as $3 \mathrm{~m}$ or better have recently been launched and are potentially capable of detecting urban flooding. They include TerraSAR-X, RADARSAT-2, and the four COSMO-SkyMed satellites.

In an operational context, reference [4] have proposed a hybrid methodology for SAR imagery, which combines radiometric thresholding and region growing as an approach enabling the automatic, objective and reliable flood extent extraction from SAR images. First results on moderate and low resolution image data indicate that the proposed method may outperform manual approaches if no training data are available even if the parameters associated with these methods are determined in a non-optimal way. The results demonstrate the algorithm's potential for accurately processing data from different SAR sensors.

Notable examples of research into automatic near real-time flood detection algorithms using single-polarisation high resolution (greater than a few metres) SAR imagery have been shown by references [5]-[6] on TerraSAR-X data and reference [7] on COSMO-SkyMed data. The algorithms by references [5]-[6] search for water as regions of low SAR backscatter using a region-growing iterated segmentation / classification approach whereas the technique by reference [7], is based on a fuzzy 
logic approach which integrates theoretical knowledge about the radar return from inundated areas based on backscattering models, with simple hydraulic considerations and contextual information. Both algorithms are very effective at detecting rural floods, but would require substantial modification to work in urban areas containing radar shadow and layover.

A semi-automatic algorithm for the detection of floodwater in urban areas using TerraSAR-X has also been developed by reference [8]. It uses a SAR simulator [9] in conjunction with LiDAR terrain data to estimate regions of the image in which water would not be visible due to shadow or layover caused by buildings and taller vegetation. Ground will be in radar shadow if it is hidden from the radar by an adjacent intervening building. The shadowed area will appear dark, and may be misclassified as water even if it is dry. In contrast, an area of flooded ground in front of the wall of a building viewed in the range direction may be allocated to the same range bin as the wall, causing layover which generally results in a strong return, and a possible misclassification of flooded ground as un-flooded. The algorithm is aimed at detecting flood extents for validating an urban flood inundation model in an offline situation, and requires user interaction at a number of stages.

Follow-up work from this was carried out by reference [10]. Here the objective was to build on a number of aspects of the existing algorithms to develop an automatic near real-time method for flood detection in urban and rural areas. In the urban area, $75 \%$ of the urban water pixels visible to TerraSAR-X were correctly detected, though this percentage reduced somewhat if the urban flood extent visible in the aerial photos and detected by TerraSAR-X was considered, because flooded pixels in the shadow/layover areas not visible to TerraSAR-X then had to be taken into account. Better flood detection accuracy was achieved in rural areas, with almost $90 \%$ 
of water pixels being correctly detected by TerraSAR-X. The algorithm assumes that high resolution LiDAR data are available for at least the urban regions in the scene, so that a SAR simulator may be run in conjunction with the LiDAR data to generate maps of radar shadow and layover in urban areas. It is therefore limited to urban regions of the globe that have been mapped using LiDAR.

To contribute to these recent developments in high performance flood detection algorithms for high resolution SAR data, we propose a simple but effective technique based on image differencing as proposed by reference [4], which may compete with existing algorithms in terms of accuracy and level of automation. For this we also focus on flood detection inside urban areas and use the TerraSAR-X image of the England summer 2007 floods as demonstration. Although this is only a single test, and different results may be obtained for other urban areas where the built environment is different to the UK case studied here, it does provide a first demonstration of the potential of the method.

\section{METHODOLOGY}

Reference [5] recently highlighted an apparent lack of traceability and standardisation in many SAR-based flood-mapping methodologies. This concern has led to the introduction of two variants of an automated and physically-based SARbased flood-mapping algorithm [4]. Both variants, which are termed M1 and M2a respectively, exploit the statistics of backscattering coefficients retrieved from SAR to segment an image into its flooded and non-flooded parts. While M1 only considers a single SAR flood image to extract pixels corresponding to "open water" via thresholding and region growing, M2a adds change detection with respect to a nonflood reference image to improve the algorithm's performance. In this study we 
introduce an enhanced version of M2a, which we term M2b. This method addresses some of the shortcomings of M2a that reference [4] identified in two representative case studies. This section provides a detailed overview of all processing steps of the flood extraction algorithm M2b, together with the associated parameters defining each process and a list of differences with respect to the M1 and M2a algorithms previously introduced. Besides standard pre-processing steps commonly involved with Level 1 SAR data, the M2b algorithm consists of four processing steps (Fig. 1).

\section{A. Statistical distribution of the "open water" backscatter}

The flood extraction algorithm uses as input Level 1 SAR data that are geo-coded, co-registered and calibrated. The first step is the estimation of the probability density function (PDF) of backscattering values associated with "open water". The aim of this processing step is the calibration of a theoretical PDF that optimally fits the empirical distribution of backscatter values from "open water" inferred from the SAR image. According to reference [13] the backscatter variability on a homogeneous surface is mainly due to speckle and the theoretical PDF that best describes the distribution of backscatter originating from a homogeneous surface is of gamma type. Here, we hypothesize "open water" to be a homogeneous surface, which means that a potential limitation of the approach and SAR mapping of inundated surfaces in general relates to the possible roughening of open water caused by emerging vegetation, wind or rainfall. We therefore assume that the PDF of type gamma can be used to estimate the distribution function of "open water" backscatter: 
$f_{\sigma_{m}^{0}}\left(\sigma^{0} / k\right)=\frac{\left(\sigma^{0}-\sigma_{1}^{0}\right)^{k-1}}{\left(\frac{\left(\sigma_{m}^{0}-\sigma_{1}^{0}\right)}{k-1}\right)^{k} \Gamma(k)} e^{-\frac{\left(\sigma^{0}-\sigma_{1}^{0}\right) \cdot(k-1)}{\left(\sigma_{m}^{0}-\sigma_{1}^{0}\right)}}$

where $k$ is the shape parameter of the gamma distribution and $\sigma_{m}^{0}$ is the gamma distribution mode. The parameter $\sigma_{1}^{0}$ is the minimum backscatter value in the SAR image, which needs to be applied so that the gamma distribution is calculated only for positive values.

Two parameters thus need to be optimized to identify the theoretical gamma function $f$ that best fits the empirical distribution of backscatter values from "open water" $h$ (i.e. image histogram). The optimization of the two parameters $k$ and $\sigma_{m}^{0}$ consists in minimizing the root mean squared error (RMSE) between the image histogram and the gamma distribution for backscatter values lower than $\sigma_{t h r}^{0}$, with the parameter $\sigma_{t h r}^{0} \geq \sigma_{m}^{0}$ representing the point where the distributions $f$ and $h$ start deviating. The optimization is performed with sequentially increasing values of $\sigma_{m}^{0}$ and $\sigma_{t h r}^{0}$ values. For each set of $\sigma_{m}^{0}$ and $\sigma_{t h r}^{0}$ values, the parameter $k$ is optimized using the nonlinear fitting process of reference [14]. The RMSE between the theoretical density function $f$ and the empirical density distribution $h$ is calculated for each parameter set and over all backscatter values lower than $\sigma_{t h r}^{0}$. Finally, the parameter set $\left(\sigma_{m}^{0}, k, \sigma_{t h r}^{0}\right)$ providing the lowest RMSE is set as optimal.

\section{B. Radiometric thresholding}

The aim of the following step of the algorithm is to extract seeds of "open water" areas from the flood image, being either individual pixels or regions. The parameter 
$\sigma_{t h r}^{0}$ represents the maximum backscatter value for which the fit between the theoretical and empirical PDF is satisfactory. For backscattering values higher than $\sigma_{t h r}^{0}$ the distribution functions $f$ and $h$ start deviating, which leads to an immediate and substantial increase of over-detected water pixels. As a matter of fact, $\sigma_{t h r}^{0}$ is considered the maximum backscatter value for which there is no significant overlap between radiometric distributions corresponding to water bodies and other land use types. Since the backscatter values from water surfaces are comparatively low, this value is used to extract the seeds of water bodies by selecting the pixels having backscatter values lower than $\sigma_{t h r}^{0}$. The thresholding yields a preliminary flood inundation map that represents the seed region for a subsequent region growing process.

Moreover, in order to be able to map permanent water bodies, the threshold

computed on the flood image, $\sigma_{t h r}^{O}$, is also applied on the reference SAR image to classify seeds of permanent water bodies. It is worth noting that these seeds include in addition to permanent water bodies other smooth surfaces with a water surface-like radar response as well as all shadow-affected areas.

\section{Region growing}

Next, the extracted water bodies, representing the seeds, are dilated using the region growing approach of reference [15]. The procedure iteratively grows the seeds until a given tolerance level is reached. The sequence of thresholding and region growing only adds pixels to the seeds that are located in the vicinity of the preliminary flood extent, thereby limiting the risk of over-detection on areas distant from the flooded area (i.e. misclassification of "dry" pixels as "wet"). The tolerance 
parameter characterises the regional homogeneity of the backscattering behaviour. The tolerance criterion adopted here is based on the percentiles of the theoretical gamma distribution of “open water" pixels.

The iterative procedure incorporates pixels with backscatter values lower than $\sigma_{r g}^{0}$, corresponding to a given percentile of the theoretical gamma distribution of "water" pixels in the image. In this study we propose a simultaneous calibration recently advocated by reference [4]. The approach optimizes the tolerance criterion $\sigma_{r g}^{0}$ together with the change detection parameter introduced in the next section.

Region growing, with the same threshold value $\sigma_{r g}^{0}$ is also applied to dilate the seeds of permanent smooth surfaces obtained from the reference image. The approach provides a mask of water surface-like radar response areas that is used to limit the region growing applied on the flood image, thereby preventing the spreading of flooded areas into permanent smooth areas.

\section{Change detection}

Reference [4] argued that flood maps resulting from region growing should include all "open water" pixels connected to the seeds. The region growing should thus extend into the high percentiles of the gamma distribution. However, the resulting over-detection needs to be removed by the subsequently applied change detection step. Change detection thus aims at removing pixels from the flood extent map that do not correspond to flood water. To do so, only pixels that significantly change their backscatter values with respect to their baseline backscatter values are kept in the flood extent map, while pixels that did not decrease their backscatter values by a minimum amount are removed. This means that the main river channel, 
which is a permanent water body, is not any longer an integral part of the flooded area.

The specific parameter of the change detection is $\Delta \sigma^{0}$, defined as the required minimum change in backscatter between the reference and the flood image for a pixel being considered as flooded. In order to determine the optimal criterion for the required minimum change in backscatter, an iterative procedure is adopted.

As mentioned earlier, the two parameters $\sigma_{r g}^{0}$ and $\Delta \sigma^{0}$ are optimized through a simultaneous calibration, minimizing the RMSE computed over the whole range of backscatter values in the flood image between the theoretical gamma distribution and the empirical distribution of "open water" pixels. This means that different threshold values, $\sigma_{r g}^{0}$, which correspond to different percentiles of the theoretical gamma distribution, are sequentially selected from an interval of plausible values, and a corresponding minimum change detection parameter $\Delta \sigma^{0}$ is optimized for each tested $\sigma_{r g}^{0}$ threshold value. For every parameter set $\left(\sigma_{r g}^{0}, \Delta \sigma^{0}\right)$, the sequence of region growing and change detection processes is applied on the area conditioned by the permanent smooth area mask. At the end of each iteration, the histogram of "flood water" pixels is computed. The corresponding empirical PDF is compared against the initially calibrated theoretical gamma distribution (1). The parameter set $\left(\sigma_{r g}^{0}, \Delta \sigma^{0}\right)$ providing the lowest RMSE value is set as optimal.

To summarize, M2b essentially represents an improved version of the M2a method introduced by reference [4]. The two algorithms both take into account a reference SAR image and include four inter-related processing steps (i.e. calibration of gamma distribution function, radiometric thresholding, region growing and change detection). However, while M2a pre-defines the region growing parameter $\sigma_{r g}^{0}$ as the 
$99 \%$ percentile of the "water" backscatter gamma distribution, M2b adds flexibility to the optimization process by calibrating the tolerance criterion $\sigma_{r g}^{0}$ that, together with the associated change detection parameter $\Delta \sigma^{0}$, minimizes the RMSE between empirical and theoretical distribution functions.

This modification implemented in $\mathrm{M} 2 \mathrm{~b}$ constitutes an important change as it renders the algorithm fully automated, without any requirement of manual user inputs. Therefore, the mapping process is believed to be entirely objective. Another important improvement is that $\mathrm{M} 2 \mathrm{~b}$, unlike $\mathrm{M} 2 \mathrm{a}$, makes use of the reference image to build a mask of permanent water surface-like radar response areas. Indeed, to render the algorithm suitable for urban flood mapping, it is necessary to mask out not only smooth surfaces like tarmac, paved roads and parking lots, but also all regions in shadow-affected areas unseen by the satellite. In urban areas the latter are particularly important as they potentially lead to a significant part of over-detected flooded areas.

It should also be noted that method M2a and its enhanced version M2b both rely on the availability of reference images acquired from the same orbital track, with the same incidence angle, polarization and resolution, and prior to the onset of flooding. Moreover, the adequate choice of a season-dependent reference image might help reducing the effects of changes in vegetation and in soil moisture conditions, as argued recently by reference [16]. With the advent of relatively new sensors such as TerraSAR-X, it can be difficult to find an image that satisfies these selection criteria. However, as image archives are gradually being built up, this should be less of a problem in the near future. If no reference image is available, method M1 can be applied. 


\section{STUDY AREA AND AVAILABLE DATASET}

This section describes the study area, the flooding event and the available remote sensing images for testing and evaluating the proposed automated flood delineation algorithm.

The image data used for this study were acquired for the 1-in-150 year flood that took place around Tewkesbury, U.K., in July 2007. Extreme rainfall intensities resulted in substantial flooding of urban and rural areas; about 1000 properties in the town of Tewkesbury were affected [17]. Tewkesbury lies at the confluence of the River Severn, flowing in from the northwest, and the River Avon, flowing in from the northeast. Bankfull discharge is approximately $350 \mathrm{~m}^{3} \mathrm{~s}^{-1}$ (or $4.5 \mathrm{~m}$ in gauged level) at the Saxons Lode gauging station $\sim 7 \mathrm{~km}$ upstream of Tewkesbury. The summer 2007 event was unusual for the study site in that the majority of the flow was derived from local rainfall. On the 20th July, two days prior to flood peak, more than $12 \mathrm{~cm}$ of rain fell on the surrounding area. The flood peak of 5.43 m Ordnance Data Newlyn was measured at Tewkesbury on July 22 with both rivers exhibiting a more rapid increase in flow than a typical autumn or winter event that may build over many weeks, with flows increasing from $100 \mathrm{~m}^{3} \mathrm{~s}^{-1}$ to $>500 \mathrm{~m}^{3} \mathrm{~s}^{-1}$ in 57 hours, between the 20th of July and the 22nd July. The river did not return to below bankfull until July 31 . In the region of interest (red box in Fig. 2) an area of $1.5 \mathrm{~km}^{2}$ was possibly flooded at the time of the TerraSAR-X overpass, according to a $2 \mathrm{~m}$ model simulation [18].

In order to demonstrate the applicability of our proposed SAR image segmentation algorithm, we define the urban area as the zone inside and in the vicinity of the built-up region of the town of Tewkesbury. 


\section{A. TerraSAR-X images}

A unique data set consisting of numerous types of remotely sensed images over one single event hydrograph were acquired over the selected study area [18]. From this dataset a stripmap TerraSAR-X image acquired on July 252007 (at 06:34 GMT, Wednesday) was selected (see Fig. 2). The image is a multi-look ground range spatially enhanced scene with $1.5 \mathrm{~m}$ pixel spacing and has a mean incidence angle of $24^{\circ}$. Its $\mathrm{H} / \mathrm{H}$ polarization mode arguably allows for the best discrimination between a SAR image's flooded and non-flooded parts [5]. At the time of the satellite overpass and image acquisition, there was relatively low wind speed and no rain [8]. Moreover, no rainfall was recorded in the 30 hours preceding the TerraSAR-X acquisition, as well as during the satellite overpass itself.

In their flood delineation study reference [8] used the single TerraSAR-X flood image together with air-borne scanning laser altimetry (LiDAR) data. Here, we also consider a dry reference image which is a post-flood image acquired from the same orbit track and with the same polarization as the flood image. This way, geometric problems related to co-registration can be limited and baseline backscatter values can be inferred. A single scene having these imaging characteristics and covering all of the azimuth extent of the target is available in the current TerraSAR-X image archive. It was acquired on July 222008 (at 06:34 GMT, Tuesday), almost exactly a year after the flood event had occurred. The flood and non-flood images have both been acquired in the same month of the year. Hence it can be assumed that the state of vegetation is similar in both images. This is important as decreases in backscatter values between any two images are caused not only by flooding, but also by changes in vegetation and soil moisture among others. Hence, it is also important to note that the gauging stations close to the town of Tewkesbury did not record any rainfall in the 
three days before the reference image was acquired. Since the weather was dry when the reference image was acquired, the effect of soil moisture fluctuations on observed decreases in backscatter values are considered as not significant for this test case.

The two images, whose characteristics are listed in Table I, have been georeferenced and calibrated. In an operational context, the reference image would ideally consist of a pre-flood satellite acquisition. However, in this particular case, given the relative novelty of a sensor such as TerraSAR-X, it was not possible to find a reference image, prior to the onset of flooding, acquired from the same orbital track and with same polarization. Therefore, a post-flood image was selected.

Particular attention has been given to an adequate co-registration of the images, as an accurate overlapping is a pre-requisite for detecting flooding-related changes in the backscattering behaviour. The accuracy of the geo-referencing has a sub-pixel precision. Next, the images have been filtered with a 5 x 5 Gamma-MAP filter to decrease the speckle contribution. This filter smoothes out the speckle granularity while preserving details, such as the contours of buildings and flooded areas [19]. It also impacts the parameterization of the gamma PDF (1) by reducing the spread of backscattering values associated with "open water". The red box area in Fig. 2 presents the area of interest for the city of Tewkesbury: it refers to a rectangular area of $1135 \times 998$ pixels (1.5 m pixel spacing) for a total surface of $\sim 3 \mathrm{~km}^{2}$.

\section{B. Validation dataset}

The validation data set, consisting of very high-resolution $0.2 \mathrm{~m}$ aerial photographs acquired during the flooding event in July 2007, enables a comprehensive evaluation of the algorithm's performance in terms of SAR-based 
flood delineation. An aircraft operated by the Environment Agency of England and Wales (EA) carried out the overflights.

The flood extent was obtained through manual photo-interpretation (Fig. 3a). Taking advantage of existing landuse maps of the area, permanent water bodies associated with rivers and canals have been removed from the validation map. While in general the delineation of flood boundaries from such high-resolution optical products is relatively straightforward, it is important to note that the flooding of densely vegetated and built-up environments can lead to some ambiguities. For instance, in the case of bare soil fields, the accurate positioning of the separation line between muddy flood waters and non-flooded areas is non-trivial.

In addition, it is important to bear in mind that the aerial photographs were acquired on July 24 (at 11:30 GMT) while the TerraSAR-X image was obtained 19 hours later on July 25 (at 06:34 GMT). Although there was no significant decrease in main river discharge between the acquisition time of aerial photographs and the TerraSAR-X overpass [20], this time gap might be responsible for some discrepancies between the SAR-derived and aerial photography-derived flooded areas. To illustrate potential discrepancies, simulations with a previously calibrated hydraulic $2 \mathrm{~m}$ LISFLOOD-FP flood model [21], have been carried out both at the aerial photographs acquisition time and at the TerraSAR-X overpass. These simulations show a reduction of the flooded area of approximately $5 \%$ between the two time steps. In particular, Fig. 3(b) shows the differences between the two simulated flood inundation maps The most notable differences can be observed on a triangular-shaped field (see the middleright part of the domain of interest) from which flood water was drained between the two overpasses according to the model simulations. This location was also problematic in terms of identifying its flooding status through photo-interpretation, as 
explained in more details in the discussion section. These factors, all unrelated to the processing of the SAR images, need to be taken into account during the analysis, as all the observed differences may not be necessarily due to the inability of the proposed algorithms for accurately extracting the flood extent from SAR imagery.

\section{RESULTS AND DISCUSSION}

This section assesses the accuracy of the classification obtained with the fully automated flood detection algorithm M2b and contrasts its performance with those of the previously introduced M1 and M2a algorithms. The section also provides insights into the added-value of reference images for flood delineation in urban areas.

\section{A. Extraction of flooded areas}

The flood extent has been extracted from the TerraSAR-X image using the three methods M1, M2a and M2b.

In particular, for method M2b, Fig. 4 illustrates the optimization of the four parameters: the mode of the "open water" backscatter gamma PDF, $\sigma_{m}^{0}$, the radiometric threshold, $\sigma_{t h r}^{0}$, the tolerance criterion for the region growing step, $\sigma_{r g}^{0}$, and the minimum $\mathrm{CD}$ value, $\Delta \sigma^{0}$. Panel (a) reports the optimization of the mode parameter while panel (d) provides the corresponding optimized gamma PDF in red together with the histogram of the backscatter values in the flood image. Panel (d) displays the value of the second parameter, $\sigma_{t h r}^{0}$ (i.e. in this case study equal to -15.5 $\mathrm{dB})$ as the maximum backscatter value for which there was no overlap between the empirical histogram and the theoretical gamma PDF. The optimized $\sigma_{t h r}^{0}$ value is also provided in Fig. 5(a), together with the backscatter histogram of pixels in the 
reference image. This value is used to derive the reference mask of permanent water surface-like radar response areas through thresholding of the reference image (Fig. 5(b)). From Fig. 4(d) and Fig. 5(a) it can be observed that for high backscatter values, there is a systematic noise in the return signal of both TerraSAR-X images. This is arguably due to the high complexity of urban topography and its considerable impacts on the high-resolution backscattering signal. Considering the region growing step of method $\mathrm{M} 2 \mathrm{~b}$, it is important to mention that the parameters $\sigma_{r g}^{0}$ and $\Delta \sigma^{0}$ are optimized together. Therefore, the subplot in panel (b) of Fig. 4 illustrates the impact that different $\sigma_{r g}^{0}$ parameters (each associated with the corresponding optimal $\Delta \sigma^{0}$ value) have on the RMSE. Similarly, panel (c) provides an example of the performance plot of parameter $\Delta \sigma^{0}$ for a given $\sigma_{r g}^{0}$ value: Fig. 4(c) refers to the optimal $\sigma_{r g}^{0}$ value of the case study. The backscatter value corresponding to the optimized $\sigma_{r g}^{0}$ value is also displayed in panels (e) and (f). Finally, panel (f) shows the empirical histogram of flood pixel values before and after change detection. The histograms in panel (f) are computed only from pixels inside the SAR-derived flooded area. The reduction of the distribution tail and the related reduction of over-detection are indicated by the empirical histogram approaching the theoretical gamma PDF.

\section{B. Evaluation at city level (quantitative analysis)}

Three flood extent maps were obtained through the application of the three image processing algorithms. The corresponding contingency matrices were computed using the evidence provided by aerial photography. The binary pattern of flooded and nonflooded pixels was compared against the reference flood map (in this case, see Fig. 3). 
The result is a matrix (or contingency table) of four possible outcomes. With respect to the reference flooded area, there are two ways for a remote sensing-derived flooded area to be correct (either by correctly representing flooded or non-flooded pixels) and two ways to be incorrect (either by erroneously under- or over-predicting the observed inundation extent). The values of the contingency matrix for all methods are reported in Table II (and also displayed as contingency maps in Fig. 6) for a quantitative evaluation of the performances. Moreover, the optimized (and/or fixed) parameter values for the region growing and the change detection are indicated.

From Table II it can be concluded that in the present case study the three algorithms provide very similar performance levels. When the evaluation is carried out at a regional scale (i.e. at city level), the differences seem to be marginal. However, methods M2a and M2b still slightly outperform method M1 with respect to all evaluation criteria listed in Table II, suggesting that change detection with respect to a non-flood reference image does provide some advantages. The results do not reflect the added-value that we expected from the methodological improvements of method M2b. This result is due to the fact that, in this particular case study, the optimized region growing threshold $\sigma_{r g}^{0}$ equals $98 \%$, which is very close to the predefined 99\% value that reference [4] proposed for M2a. Here, the trade-off involves a controlled growing of the seed region in order to be able to limit the over-detection of flooded areas. While the latter can be partly removed by the subsequent change detection, the results indicate that the reduced over-detection comes at the cost of an increased under-detection of flooded areas. The results also indicate that method M2b, which provides an optimal empirical distribution with respect to the targeted gamma distribution of "open water" backscatter values, does not necessarily generate a more accurate flood inundation map than M2a. On a more positive note, it can be observed 
that the simultaneous optimization of region growing threshold $\sigma_{r g}^{0}$ and change detection parameter $\Delta \sigma^{0}$, computed by minimizing the RMSE between empirical and theoretical distribution functions, led to the maximum value of correctly detected pixels (81.7\% as reported in Table II). Moreover, from Fig. 7 it can be observed that in this case study the optimum parameter set also yields the best performance with respect to the validation data.

A comparison with the flood extent detected for the same test case with the semiautomatic procedure of reference [8] cannot be carried out in a very meaningful way due to the fact that the input data sets in both studies differ. Reference [8] took advantage of a regional DEM so that SAR-derived water ground heights smoothly vary along the river reach. Furthermore, reference [8] did not make use of a pre-flood reference image. The comparison of contingency matrices reveals that the M2b method performance of $81.7 \%$ of correctly detected pixels is rather close to the percentage of $85.4 \%$ obtained with the flood inundation map provided by reference [8] on a common area of interest and reference dataset. This result indicates that topography data could be used more efficiently than pre-flood reference images for increasing the accuracy of SAR-derived flooded areas. However, this assessment needs to be confirmed in future studies.

To better appreciate the advantages of these methodological enhancements it is worth analyzing the PDF of backscattering values associated with pixels located inside the flood inundation maps, the latter corresponding either to the validation map obtained from aerial photographs or the flood extent maps computed with the different versions of the image-processing algorithm. The different PDFs are displayed in Fig. 8. It becomes evident from the panels that the PDF of "flood water" pixels from high-resolution photos is reasonably close to a gamma distribution, albeit 
characterized by a heavy tail end. M1 does enable the identification of a majority of water pixels, but it misses out the tail of the distribution. M2a yields a better performance, as it adds more pixels to the flood extent, thereby reducing the number of under-detected flood pixels. However, there is still a tendency to slightly overestimate part of the tail of the theoretical gamma PDF. Because of its enhanced change detection procedure, the M2b method is capable of growing the seeds further into the high percentiles of the gamma distribution, thereby further reducing the heavy tail end while keeping the PDF of detected water pixels closer to the theoretical PDF. It is worth noting here that the PDF of backscattering values inside the area delimited by the high-resolution photos exhibits a particular tail that is missed by all three versions of the flood detection algorithm. Surprisingly, the high number of pixels with associated high backscatter values is not only due to the expected increased backscatter response from urban structures. In fact, probability distributions from pixels located in rural areas exhibit the same heavy tail end as pixels located in urban areas (Fig. 9). Further research is needed to get a better understanding of the particular shape of the PDF of backscatter values. One possible explanation, can be that some of the pixels changed their status from "flooded" to "non-flooded" between the two data acquisitions, as already illustrated in Fig. 3b.

From this first overview of results, it can be concluded that the strength of change detection is that it allows the region growing to extend further into the high percentiles of the gamma distribution as it efficiently removes part of the resulting over-detection. More case studies are needed before a generalization of these findings can be done in a meaningful way. Nevertheless, these preliminary results corroborate those reported by reference [4] in case studies dealing with coarse and moderate resolution SAR imagery. 
On the selected domain (i.e. rectangular area of $1135 \times 998$ pixels) the running time of the complete process on an Intel(R) Core (TM) 2Quad CPU, 2.66Ghz and 3.24 GB RAM is less than 30 minutes, indicating the appropriateness of the method also for near real-time applications.

\section{1) Analysis of errors: the problem of unseen regions}

One feature that requires special attention relates to regions in a SAR image that cannot be seen by the radar sensor because of its side-looking nature. The affected regions are commonly referred to as 'shadow' and 'layover'. In the context of urban flood mapping 'shadow' and 'layover' are due to geometric distortions caused mainly by the presence of buildings. Their impact on SAR-based flood mapping is twofold. First, flooding does not impact the radar response from shadow areas and, consequently, SAR-based detection of flooded shadow areas is not possible (i.e. problem of under-detecting floods). Second, the low radar response from shadow regions might erroneously lead to their classification as 'flooded' even in the case they are not (i.e. problem of over-detecting floods). Here, we assume that the resulting over-detection might be addressed through change detection since urban shadow areas do not change between two images acquired from the same track. This is confirmed by the reduction in over-detection shown in Table II. Moreover, due to double-bounce reflection effects, the urban layover backscatter could be different in the flood and reference images. This phenomenon typically occurs in vegetated areas, where flooding yields an increased backscatter due to the double-bouncing between the flooded ground and branches or leaves, resulting in a higher return signal in the flood image. A similar mechanism of multiple reflections between flooded streets and walls can potentially result in a brighter backscatter in the urban areas covered by the flood 
image. Classification errors are expected to be higher in urban areas than in forested regions [22] and therefore the layover contribution should be taken into account when mapping flooded urban areas. In fact, the inherent under-detection problem can only be addressed through technological advances (e.g. look angles closer to nadir) or the use of ancillary data (e.g. topography data).

For the imaging characteristics of the TerraSAR-X image acquired on July 25 2007, reference [8] computed a mask of areas affected by 'shadow' and 'layover' in the city of Tewkesbury (Fig. 10). They used the German Aerospace Center (DLR) SAR end-to-end simulator (SETES) in conjunction with air-borne scanning laser altimetry (LiDAR) data to estimate regions of the image in which water would not be "visible" to the instrument. In this case study we made use of the shadow/layover mask from reference [8] to evaluate the risk of misclassifying pixels in areas not "visible" to the SAR sensor.

In the area of interest (red box in the relevant figures), the shadow/layover mask of reference [8] covers a total area of $\sim 1 \mathrm{~km}^{2}$, which is a significant percentage of the total area selected for the analysis $\left(\sim 3 \mathrm{~km}^{2}\right)$. However, referring to the validation map, the flooded area not visible to the satellite reduces to $0.25 \mathrm{~km}^{2}$, over a total flood extent of $1.22 \mathrm{~km}^{2}$ (see Table III). Moreover, due to the $24^{\circ}$ look angle, in this particular case study the effect of layover is greater than shadow, as it covers a much larger flooded area. This is mostly due to the diffuse presence of hedges along the borders of the different fields in the rural areas.

As flooding in shadow/layover areas is undetectable for SAR, the corresponding regions would need to be delineated a priori and considered as areas with an "unidentifiable status of flooding". In fact, even if a flood is correctly classified in a shadow region, this result should be viewed as an error as the right answer is obtained 
for the wrong reason. As the objective of the developed method was to generate a mask of surfaces that produce a radar signal response similar to that of inundated areas in order to constrain the flood extent outside the shadow areas, in the following we focus only on the overlap between the obtained flood extent and the shadow areas derived by reference [8]. Note that the shadow mask itself, obtained with the SAR simulator and the LiDAR data, might contain some degree of uncertainty. However, we noticed that the number of such pixels was not significant in comparison to the total number of extracted flood pixels (see Table III). In general, the overlap between the SAR-derived flood extent and the shadow mask is restricted to the border regions of large clusters of pixels, which were correctly classified as "flooded". Furthermore, it can be observed from the results in Table III that M2b helps in significantly reducing the number of pixels classified as "flood water" in the shadow regions. This is due to the fact that parts of the shadow-affected areas are included in the mask of permanent water surface-like radar response areas described earlier. By considering a reference image acquired from the same orbital track as the target image, the method termed M2b reduces the risk of classifying 'shadow' areas as "flooded".

\section{Evaluation at street level (qualitative/thematic analysis)}

The benefits of using a reference image (including the masking of permanent smooth areas) become obvious when looking at the spatial distribution of errors (Fig. 6). The application of algorithms M2a and M2b leads to the expected reduction of misclassified pixels in urban areas. Numerous scattered clusters of pixels that were initially erroneously classified as "flooded" could be removed, thereby significantly reducing over-detection. In Table IV a thematic analysis with a special focus on urban features complements the quantitative analysis presented earlier (Table II). 
The objective is to understand the advantages and limitations of the three variants of the SAR-based flood delineation algorithms for correctly identifying flooding in urban areas. From the results depicted in Table IV, it can be observed that in spite of the high-resolution SAR imagery used in this study, the detection of flooding in builtup environments remains a very challenging task. All algorithms struggle to recognize the flooding status of many small-scale features that might be crucial as their state of flooding could mean significant interruptions of everyday life. However, overall, the enhanced algorithm M2b performs best with a slightly reduced number of misclassified areas. In particular, M2b enables the a priori delineation of areas characterized by specular-like reflections (i.e. areas with permanent water surface-like radar responses). This is helpful given that smooth areas (e.g. R2 \& R3) tend to be systematically classified as flooded by M1 and, to a lesser extent, by M2a. On the other hand, more open areas, such as the main roads R12 and R13, are correctly classified by all three methods. It is worth mentioning that, despite these somewhat encouraging results, M2b fails to correctly delineate flooding in many densely vegetated and built-up environments.

These errors will be analyzed in more detail in the following sections. In this analysis we will consider ancillary data (e.g. land use map, oral communications from local experts) to better understand the reasons that are at the origin of the remaining misclassifications. Moreover, the mask of the region unseen by the satellite, i.e. shadow and layover, has also been taken into account for error detection at street level. 


\section{1) Analysis of errors: the problem of over detection}

As it can be seen from the urban flood maps presented in Fig. 6 both over- and under-detection are reduced as a result of applying the M2b algorithm rather than its predecessors. This is particularly evident in the case of the large shopping mall labelled R3. Due to the flatness of its roof and resulting specular reflection it was erroneously classified as flooded by M1, while M2a and M2b correctly excluded it from the flooded area. This emblematic example best illustrates the potential added value of reference images as they enable the a priori identification of the majority of smooth areas.

Similarly, other wide flat regions, such as parking lots and airfields, are recognizable in the reference image. For instance, the region labelled R1 corresponds to large parking lot composed of three parts. M2b completely removes one of them from the flood extent map, while the two other parts are significantly reduced in size. The sub-optimal performance of M2b is arguably due to a difference in the number and placement of vehicles at the time of the two satellite overpasses. In very high resolution SAR imagery the presence or not of an object like a car inevitably impacts the radar response. This necessarily influences the capability of the M2b algorithm to reliably identify areas of smooth tarmac and unfortunately may not be resolvable at all, for obvious reasons.

The region labelled $\mathrm{R} 2$, an area both flat and made of tarmac but not used as a parking space, shows the capability of M2b to avoid the typical misclassifications of smooth areas as flooded.

Finally the thematic analysis confirms the algorithm's ability for identifying permanent water bodies. The permanently flooded bed of the River Avon and some adjacent boat marinas are removed from the flood extent map when taking into 
account the reference image: this becomes evident when looking at the areas of over detection in the panels (b) and (c) of Fig. 6. Clearly, this result is not achievable with a single flood image, as M1 would invariably classify permanent water bodies as flooded (see panel (a) of Fig. 6).

Despite the previously mentioned ability of M2b to detect areas with permanent low backscatter values, there are still some shadow-affected areas that are erroneously classified as "flooded". A typical example is a large inclined rooftop in region R9. This is classified as "flooded" by all three methods due to the fact that one side is not "visible" to the SAR sensor. Other examples of this behaviour can be found on various inclined rooftops in the $\mathrm{R} 7$ region.

To summarize, some risk of over-detecting flooded areas in built-up environments inevitably remains. Non-flooded areas that appear smooth and water-surface like at radar wavelengths as well as areas unseen by the satellite because of the side-looking nature of SAR systematically produce very low signal returns and are not easily distinguishable from flooded areas. The results of this study suggest that taking into account the baseline backscatter values from "dry" reference images partly addresses the problem. Wide, open areas of tarmac or concrete (roads, parking lots, airfields etc.) can be identified and removed from the final flood map (or, alternatively, categorized as areas impossible to classify), while the situation is more problematic with shadow areas. To check the plausibility of both types of regions to be flooded, we expect that the use of high-resolution high-precision DEM data may be helpful. More research on the integration of additional data sources into the image-processing algorithm is needed for this to provide significant advantages. 


\section{2) Analysis of errors: the problem of under detection}

With respect to the problem of under-detecting the true flood extent using SAR observations, the results depicted in Table II indicate that method M2b leads to a decrease in performance. In fact, the percentage of under-detected flood pixels rises from $15.6 \%$ obtained with the initial M2a method to its M2b-related value of $16.2 \%$. However, it has to be underlined that this type of error is generally to be found on the edge of inundated fields or in the vicinity of the main riverbed with tall vegetation surrounding the areas. While the algorithm accurately retrieves most of the flooded areas in wide, open areas, it can be observed that it systematically fails to retrieve flooding under the vegetation canopy. These errors are not related to the imageprocessing algorithm; rather they are due to the fact that with X-band radar systems volume scattering originating from the vegetation canopy causes increased signal return (i.e. layover). Furthermore, as already mentioned in paragraph 3.2, it cannot be ruled out that the validation flood extent itself is affected by a slight overestimation, as it was acquired closer to peak discharge than the satellite images. This could also at least partly explain the under detection documented in the contingency matrix. Also, the uncertainties in the delineation of the flood validation extent form aerial photography are expected to have some marginal effect.

For example, an important area of apparent under-detection is the triangular shaped field labelled R15. However, a closer look at the data reveals that due to the time difference between the acquisitions of aerial photographs satellite imagery, it is likely that that most of the floodwater was drained from the field in the 19 hours preceding the TerraSAR-X acquisition. This hypothesis is confirmed by hydraulic model simulations (see Fig. 3(b)). 
The roughening of water surfaces due to wind is another inherent and potentially significant limitation of the algorithm proposed in this study. When there are regular waves on the surface of the water, Bragg resonance can result in very high signal returns [23]. The misclassification of the area labelled R18 as non-flooded represents a typical example. From the air photos and model simulations there can be no doubt about the flooding of the area. However, waves are clearly identifiable on the standing water. This renders accurate flood detection extremely difficult (if not impossible), as it violates the algorithm's main underlying assumption of flooded areas behaving as specular reflectors.

\section{CONCLUSIONS}

This study proposes a promising methodology that is shown to be capable of providing satisfactory results in mapping flood extent in a challenging case study However, some further improvements are still necessary before the deployment of a fully automated SAR-based flood delineation algorithm operating in a near-real time can be envisaged.

The proposed algorithm shares some of the characteristics advocated by reference [5]. In fact, since no manual (and subjective) input is required from the end user, the algorithm enables an automated, objective and repeatable flood detection. The algorithm is computationally efficient and operates with minimum data requirements, considering as input data a flood image and a reference image acquired before or after the flooding.

The difficulty of detecting flooded areas in a built-up environment could be partially addressed by a change detection approach that makes use of pre- or postflood reference images available in the data archives of satellite data providers. In 
particular, the shadow effect stemming from man-made structures can be taken into account through a mask of permanent water surface-like radar response areas. This approach overcomes the need of a high-resolution DEM and a SAR simulator for determining shadow regions that are not visible to the satellite. On the other hand, it requires a reference image with the same imaging characteristics as the flood image. While the number of suitable candidate images can be very limited in case of relatively new satellites, such as TerraSAR-X, it is important to note that image archives are gradually being built up, which will progressively increase the likelihood of finding adequate reference images in the online archives.

In order to further improve the method, we aim at taking advantage of topographic and land use data, which are available at global scale, albeit with variable accuracy and resolution. We hypothesize that such ancillary data will help to reduce the elevation curvature along the flood edges as argued by reference [8] and to identify parts of the under-detection caused by emerging objects such as trees of buildings.

We consider this study to be timely because there is a clear need for rapidly acquiring, processing and distributing hydrology-related information derived from SAR imagery. For near real-time applications in hydrology, where flood extent data is systematically assimilated into hydrologic-hydraulic models, the value of remote sensing data is much higher if rapidly available [24]-[25].

\section{AKNOWLEDGMENTS}

This study was part of the HYDRASENS project, financed by the National Research Fund (FNR) of the Grand Duchy of Luxembourg and the Belgian Federal Science Policy Office in the framework of the STEREO II research programme (Contract nr. SR/00/100). The authors wish to thank the Environment Agency of England and 
Wales for the aerial photography of the Tewkesbury flood and the UK Meteorological Office for granting access to the NERC BADC for the rainfall records used in the analysis. The TerraSAR-X flood image was received under DLR SSS project HYD0363. 


\section{REFERENCES}

[1] D. E. Alsdorf, E. Rodriguez, and D. P. Lettenmaier, "Measuring surface water from space," Rev. Geophys., vol. 45, no. 2, pp. 1-24, May 2007.

[2] W. A. Marcus and M. A. Fonstad, "Optical remote mapping of rivers at sub-meter resolutions and watershed extents," Earth Surf. Processes Landforms, vol. 33, no. 1, pp. 4-24, Jan. 2008.

[3] G. Schumann, P. D. Bates, M. S. Horritt, P. Matgen, and F. Pappenberger, "Progress in integration of remote sensing-derived flood extent and stage data and hydraulic models," Rev. Geophys., vol. 47, Nov. 2009.

[4] P. Matgen, R. Hostache, G. Schumann, L. Pfister, L. Hoffmann, and H. H. G. Savenije, "Towards an automatic SAR-based flood monitoring system. Lessons learned from two case studies," Physics and Chemistry of The Earth, vol. 36, no. 7-8, pp. 241-252, 2011.

[5] S. Martinis, A. Twele, and S. Voigt, "Towards operational near real-time flood detection using a split-based automatic thresholding procedure on high resolution TerraSAR-X data," Nat. Hazards Earth Syst. Sci., vol. 9, no. 2, pp. 303-314, 2009.

[6] S. Martinis, A. Twele, and S. Voigt, "Unsupervised extraction of flood-induced backscatter changes in SAR data using Markov image modeling on irregular graphs," IEEE Trans. Geosci. Remote Sens., vol. 49, no. 1, pp. 251-263, 2011.

[7] L. Pulvirenti, N. Pierdicca, M. Chini, and L. Guerriero, "An algorithm for operational flood mapping from Synthetic Aperture Radar (SAR) data using fuzzy logic," Nat. Hazards Earth Syst. Sci., vol. 11, pp. 529-540, Feb 2011.

[8] D. C. Mason, R. Speck, B. Devereux, G. Schumann, J. Neal, and P.D. Bates, "Flood detection in urban areas using TerraSAR-X," IEEE Trans. Geosci. Remote Sens., vol. 48, no. 2, pp. 882-894, Feb. 2010. 
[9] R. Speck, P. Turchi, and H. Süß, “An end-to-end simulator for high resolution spaceborne SAR systems," in Proc. SPIE Defense Security, 2007, vol. 6568, p. 656 $80 \mathrm{H}$

[12] D. C. Mason, I. J. Davenport, J.C. Neal, G. J-P. Schumann, and P. D. Bates, "Near real-time flood detection in urban and rural areas using high resolution synthetic aperture radar images," IEEE Trans. Geosci. Remote Sens., in press, 2012.

[13] F. Ulaby, R. Moore, and A. Fung, Microwave remote sensing, active and passive, Vol. III: Volume scattering and emission theory, advances system and applications. Norwood (MA), USA: Artech House, 1986.

[14] G. A. F. Seber and C. J. Wild, Nonlinear Regression. Berlin: John Wiley \& Sons, 2003.

[15] R. M. Haralick and L. G. Shapiro "Image segmentation techniques," Comput. Vision Graph. Image Process., vol. 29, no. 1, pp. 100-132, Jan. 1985.

[16] R. Hostache, P. Matgen, W. Wagner, and L. Pfister, "Change detection approaches to flood extent mapping: How to select the best pre-flood reference image from online archives?," Geophysical Research Letters, under review.

[17] Environment Agency, Review of 2007 summer floods. Dec. 2007. Available online at http://publications.environment-agency.gov.uk/PDF/GEHO1107BNMI-EE.pdf

[18] G. J-P. Schumann, J. C. Neal, D. C. Mason, and P. D. Bates, "The accuracy of sequential aerial photography and SAR data for observing urban flood dynamics, a case study of the UK summer 2007 floods," Remote Sens. Environ., vol. 115, no. 10, pp. 2536-2546, 2011. 
[19] A. Lopès, E. Nezry, R. Touzi, and H. Laur, "Structure detection and statistical adaptive speckle filtering in SAR images," Int. J. Remote Sens., vol. 14, no. 9, pp. 1735-1758, 1993.

[20] H. Zwenzner and S. Voigt, "Improved estimation of flood parameters by combining space based SAR data with very high resolution digital elevation data," Hydr. Earth Syst. Sci., vol. 13, no. 5, pp. 567-576, May 2009.

[21] J.C. Neal, G. Schumann, T. Fewtrell, M. Budimir, P. D. Bates, and D. C. Mason, "Evaluating a new LISFLOOD-FP formulation with data from the summer 2007 flood in Tewkesbury, UK," J. of Flood Risk Manage., vol. 4, no. 2, pp. 88-95, Mar. 2011.

[22] E. Malnes, S. Solbo, I. Lauknes, G. J. Evertsen, T. A. Tollefsen, I. Solheim, and M. Indregard, "Floodman-global near real-time flood monitoring for hydrological users," International conference: Innovation, advances and implementation of flood forecasting technology, 17 to 19 October 2005, Tromsø, Norway, 2005.

[23] D. O'Grady, M. Leblanc, and D. Gillieson, “Use of ENVISAT ASAR Global Monitoring Mode to complement optical data in the mapping of rapid broad-scale flooding in Pakistan," Hydrol. Earth Syst. Sci. Discuss., vol. 8, no. 3, pp. 5769-5809, 2011.

[24] P. Matgen, M. Montanari, R. Hostache, L. Pfister, L. Hoffmann, D. Plaza, V. R. N. Pauwels, G. J. M. De Lannoy, R. De Keyser, and H. H. G. Savenije, “Towards the sequential assimilation of SAR-derived water stages into hydraulic models using the Particle Filter: proof of concept," Hydrol. Earth Syst. Sci., vol. 14, no. 9, pp. 1773$1785,2010$.

[25] L. Giustarini, P. Matgen, R. Hostache, M. Montanari, D. Plaza, V. R. N. Pauwels, G. J. M. De Lannoy, R. De Keyser, L. Pfister, L. Hoffmann, and H. H. G. 
Savenije, "Assimilating SAR-derived water level data into a flood model: a case study" Hydrol. Earth Syst. Sci., vol. 15, no. 7, pp. 2349-2365, 2011. 


\section{FIGURE CAPTIONS}

Fig. 1. General scheme of the three processing steps of the flood detection algorithm M2b.

Fig. 2. (a1) Flood image (July 25 2007) and (b1) post-flood reference image (July 22 2008). Zoom in the area of interest (city of Tewkesbury) for (a2) the flood image and (b2) the reference one.

Fig. 3. (a) Flood validation map obtained from high resolution aerial photography on July 242007 at 11:30: the permanent water bodies are also displayed; (b) comparison between the LISFLOOD computed flood extent at the time of aerial photographs acquisition (July 24 2007, 11:30 GMT) and TerraSAR-X overpass (July 25 2007, 6:34 GMT).

Fig. 4. Optimization of the parameters of the automated algorithm for M2b method: Gamma pdf mode, $\sigma_{m}^{0}$, backscatter threshold, $\sigma_{t h r}^{0}$, region growing threshold (or maximum water backscatter), $\sigma_{r g}^{0}, \mathrm{CD}$ threshold, $\Delta \sigma^{0}$; the backscatter histogram of the flood image is also displayed in dark blue colour.

Fig. 5. (a) Backscatter histogram of the reference image with superimposed the threshold value ${ }^{\sigma}$ thr , computed on the flood image; (b) reference mask: pixels in the reference image with values lower than ${ }^{o}$ thr .

Fig. 6. Contingency map deriving from method: (a) M1, (b) M2a, (c) M2b. For sake of clearness in the representation, the displayed maps have been cleaned by neighbourhood analysis in post-processing step. 
Fig. 7. RMSE values computed for different region growing thresholds (M2b method) during the optimization process and corresponding performances in terms of correctly predicted pixels (as flooded and as non-flooded).

Fig. 8. Backscatter probability density function of water pixels from the high resolution (HR) photographs and water pixels from the method: (a) M1, (b) M2a, (c) M2b. The histograms refer to the algorithm output, with no post-processing cleaning step included.

Fig. 9. (a) Main rural and urban areas overlapped on the pixels in the flood image covered by water according to the high resolution aerial photographs; (b) corresponding backscatter probability density functions.

Fig. 10. Mask of regions unseen by TerraSAR-X due to shadow and layover, from reference [8]. 
TABLES

TABLE I

CHARACTERISTICS OF THE AVAILABLE IMAGES (STRIPMAP MODE) FOR THE ANALYZED FLOOD EVENT.

\begin{tabular}{cccccccccc}
\hline IMAGE & Date & track & orbit & $\begin{array}{c}\text { pixel } \\
\text { spacing } \\
(\mathbf{m})\end{array}$ & $\begin{array}{c}\text { ground } \\
\text { resolution } \\
(\mathbf{m})\end{array}$ & band & $\begin{array}{c}\text { wave } \\
\text { length } \\
(\mathbf{G H z})\end{array}$ & $\begin{array}{c}\text { Average mean } \\
\text { polarization } \\
\text { incidence angle } \\
\text { on study area } \\
\left({ }^{\circ}\right)\end{array}$ \\
\hline flood & $\begin{array}{c}\text { July 25 } 2007 \\
6: 34\end{array}$ & descending & 109 & 1.5 & 3 & $\mathrm{X}$ & 9.6 & $\mathrm{H} / \mathrm{H}$ & 24 \\
reference & $\begin{array}{c}\text { July } 222008 \\
6: 34\end{array}$ & descending & 109 & 1.5 & 3 & $\mathrm{X}$ & 9.6 & $\mathrm{H} / \mathrm{H}$ & 24 \\
\hline
\end{tabular}

TABLE II

QUANTITATIVE EVALUATION OF TERRASAR-X DERIVED FLOOD

EXTENT.

\begin{tabular}{lccccccc}
\hline & $\sigma_{r g}^{0}$ & $\mathbf{R G}_{\text {thr }}$ & $\Delta \sigma^{0}$ & $\begin{array}{c}\text { over } \\
\text { detection }\end{array}$ & $\begin{array}{c}\text { under } \\
\text { detection }\end{array}$ & $\begin{array}{c}\text { total } \\
\text { good }\end{array}$ & $\begin{array}{c}\text { total } \\
\text { error }\end{array}$ \\
\hline & $(\mathrm{dB})$ & $(\%)$ & $(\mathrm{dB})$ & $(\%)$ of the & area of interest, red box in Figures \\
\hline M1 & -13.4 & 96 & - & 2.8 & 15.6 & 81.6 & 18.4 \\
M2a & -11.7 & 99 & -3.1 & 2.6 & 15.6 & 81.8 & 18.2 \\
M2b & -12.5 & 98 & -3.0 & 2.1 & 16.2 & 81.7 & 18.3 \\
\hline
\end{tabular}

TABLE III

QUANTITATIVE ANALYSIS OF WATER PIXELS (PIXEL SIZE 1.5M) IN THE SHADOW REGIONS (MASON ET AL., 2010).

\begin{tabular}{cccc}
\hline & $\begin{array}{c}\mathbf{n}^{\circ} \text { of water } \\
\text { pixels } \\
\text { in shadow }\end{array}$ & $\begin{array}{c}\mathbf{n}^{\circ} \text { of } \\
\text { water pixels }\end{array}$ & $\begin{array}{c}\text { water pixels } \\
\text { in shadow } \\
(\boldsymbol{\%})\end{array}$ \\
\hline M1 & 8648 & 374060 & 2.3 \\
M2a & 8738 & 371734 & 2.3 \\
M2b & 7304 & 357616 & 2.0 \\
\hline
\end{tabular}


TABLE IV

IMPROVEMENT DERIVING FROM THE USE OF A REFERENCE IMAGE:

COMPARISON OF THE DIFFERENT METHODS FOR SOME REGIONS, WITH

A SPECIAL EMPHASIS ON URBAN FEATURES. SEE FIG. 6 FOR THE

LOCATION OF STREETS, CROSSINGS AND URBAN/RURAL AREAS (THE CORRECTLY CLASSIFIED REGIONS OF EACH METHOD ARE IN BOLD FONT).

\begin{tabular}{|c|c|c|c|c|c|}
\hline ID & region & HR photographs & method M1 & method M2a & method M2b \\
\hline R1 & parking lots & non-flooded & flooded & partially flooded & partially flooded \\
\hline $\mathrm{R} 2$ & tarmac area & non-flooded & flooded & non-flooded & non-flooded \\
\hline R3 & $\begin{array}{l}\text { supermarket roof } \\
\text { (Morrisons Store) }\end{array}$ & non-flooded & flooded & non-flooded & non-flooded \\
\hline $\mathrm{R} 4$ & road crossing & non-flooded & non-flooded & non-flooded & non-flooded \\
\hline R5 & $\begin{array}{l}\text { Road } \\
\text { (Barton Road) }\end{array}$ & non-flooded & flooded & flooded & flooded \\
\hline R6 & field on hillslope & non-flooded & flooded & flooded & flooded \\
\hline R7 & roof & non-flooded & flooded & flooded & non-flooded \\
\hline $\mathrm{R} 8$ & urban area & non-flooded & partially flooded & less flooded & less flooded \\
\hline R9 & roof & non-flooded & flooded & flooded & flooded \\
\hline $\mathrm{R} 10$ & road crossing & non-flooded & flooded & partially flooded & partially flooded \\
\hline R11 & $\begin{array}{l}\text { Road } \\
\text { (East Street) }\end{array}$ & non-flooded & non-flooded & flooded & non-flooded \\
\hline $\mathrm{R} 12$ & $\begin{array}{l}\text { Road } \\
\text { (Chance Street) }\end{array}$ & non-flooded & non-flooded & non-flooded & non-flooded \\
\hline $\mathrm{R} 13$ & $\begin{array}{l}\text { road } \\
\text { (High Street) }\end{array}$ & non-flooded & non-flooded & non-flooded & non-flooded \\
\hline $\mathrm{R} 14$ & parking lot & partially flooded & flooded & partially flooded & partially flooded \\
\hline $\mathrm{R} 15$ & field & flooded (dubious) & non-flooded & non-flooded & non-flooded \\
\hline $\mathrm{R} 16$ & $\begin{array}{l}\text { road } \\
\text { (Ashchurch Road) }\end{array}$ & flooded & partially flooded & partially flooded & partially flooded \\
\hline $\mathrm{R} 17$ & road crossing & flooded & non-flooded & non-flooded & non-flooded \\
\hline $\mathrm{R} 18$ & parking lot & flooded & partially flooded & partially flooded & partially flooded \\
\hline R19 & urban area & flooded & partially flooded & partially flooded & partially flooded \\
\hline $\mathrm{R} 20$ & urban area & flooded & non-flooded & non-flooded & non-flooded \\
\hline $\mathrm{R} 21$ & $\begin{array}{l}\text { Road } \\
\text { (Knights Way) }\end{array}$ & flooded & non-flooded & non-flooded & non-flooded \\
\hline
\end{tabular}




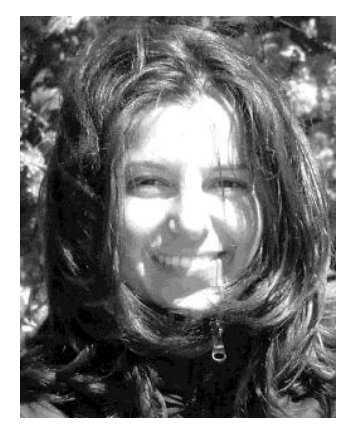

Laura Giustarini received the B.Sc. and M.Sc. degrees in environmental engineering from the University of Perugia, Perugia, Italy, in 2003 and 2006, respectively. She has worked for the National Research Council, Research Institute for Geo-Hydrologicl Protection, Perugia, Italy. Since 2010, she has been with the Department of Environment and Agro-Biotechnologies, Public Research Centre - Gabriel Lippman, Belvaux, Luxembourg. Her current research interests are the integration, through data assimilation techniques, of radar remote sensing into coupled hydrologic and hydraulic models for surface water management.

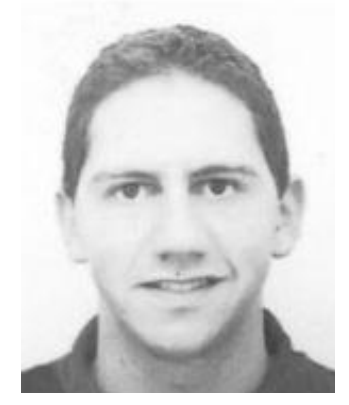

Renaud Hostache received the M.Sc. degree in mechanics of geophysical media and environment from the Joseph Fourier University, Grenoble, France, in 2003 and the Engineering degree in hydraulics and environmental sciences from Grenoble Institute of Technology-National School of Hydraulics and Mechanism of Grenoble, Grenoble. He has undertaken his Ph.D. research work with the Cemagref, Montepellier, Fgrance. His Ph.D. investigated the fine 3D characterization of flood hazard, owing to datellite imagery and its integration in flood inundation models. He received the Ph.D. degree in water sciences from the National School of Agriculture, Water and Forest Engineering, Montepellier, in 2006. Since 2007, he has been with the Department of Environment and Agro-Biotechnologies, Public Research Centre - Gabriel Lippman, Belvaux, Luxembourg. His current research interests are focused on the integration of remote-sensing observations in hydraulic models in the hydrologic and hydraulic model uncertainty characterization and reduction.

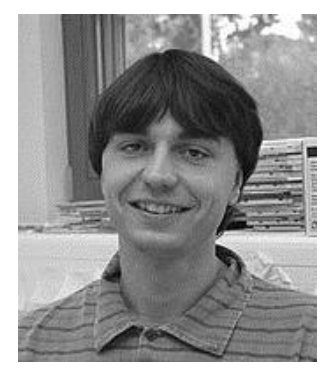


Patrick Matgen earned his M.Sc. in environmental engineering at the Ecole Polytechnique Fédérale de Lausanne (Switzerland). In 2011 he was awarded the Ph.D degree from the water resources section of the Technical University in Delft (The Netherlands) for his dissertation on the retrieval of surface and subsurface water from microwave remote sensing observations and the integration of the data with flood prediction systems. He currently holds the position of project leader responsible for microwave remote sensing and hydrologic-hydraulic modeling projects at the Centre de Recherche Public - Gabriel Lippmann (Grand Duchy of Luxembourg).

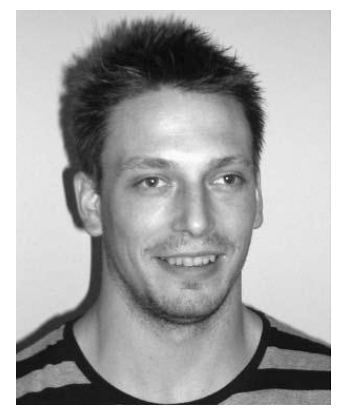

Guy J.-P. Schumann received the M.A. degree in geography and environmental science and the M.Sc. degree in remote sensing image processing and applications from the University of Dundee, Dundee, U.K., in 2003 and 2005, respectively, and the Ph.D. degree in collaboration with the Public Research Centre-Gabriel Lippmann, Belvaux, Luxembourg, in 2008. He is currently with the School of Geographical Sciences, University of Bristol, Bristol, U.K. His research interests include flood hydrology and hydraulics and remote sensing in hydrology, in particular, radar remote sensing for flood hydrology and management. Dr. Schumann was the recipient of a Great Western Research Fellowship in Hydrology from the School of Geographical Sciences, University of Bristol.

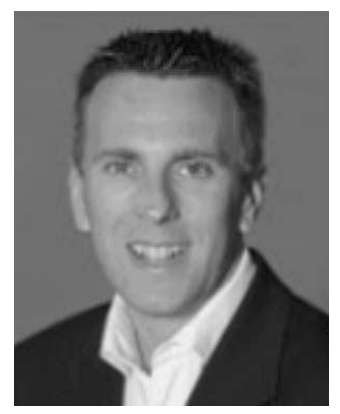

Paul D. Bates received the Ph.D. degree from the University of Bristol, Bristol, U.K., in 1993 with support from a Natural Environmental Research Council studentship. Subsequently, he has worked with the University of Bristol as a Postdoctoral Researcher and Lecturer and has been a Full Professor since 2003. He is currently the Director of the Hydrology Research Group with the School of Geographical Sciences, Bristol. He has been a Visiting Scientist with the Laboratoire National D'Hydraulique, Princeton University, Paris, and the European Union Joint Research Centre, Ispra, Italy. His research concerns the development and analysis of numerical models for predicting river flood flows, principally using data derived from remote sensing sources. He has specific interests in spatial prediction, risk, and uncertainty. Prof. Bates is the Editor-in-Chief of the International Journal of River Basin Management. 


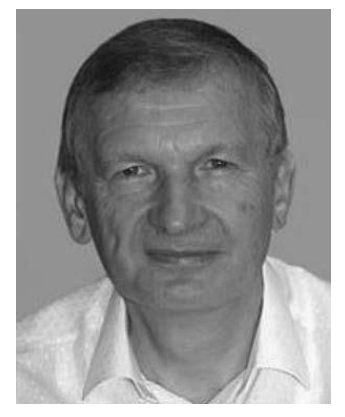

David C. Mason received the B.Sc. and Ph.D. degrees in physics from the University of London, London, U.K., in 1963 and 1968, respectively. He has worked for the U.K. Medical Research Council and Plessey Electronic Systems Research. Since 1984, he has been with the Natural Environment Research Council Environmental Systems Science Centre, University of Reading, Reading, U.K., carrying out research on the automated extraction of information from remotely sensed data and linking these data to environmental models. His current interests include using remotely sensed data for validation and parameterization of river flood models and assimilation into coastal morphodynamic models. 


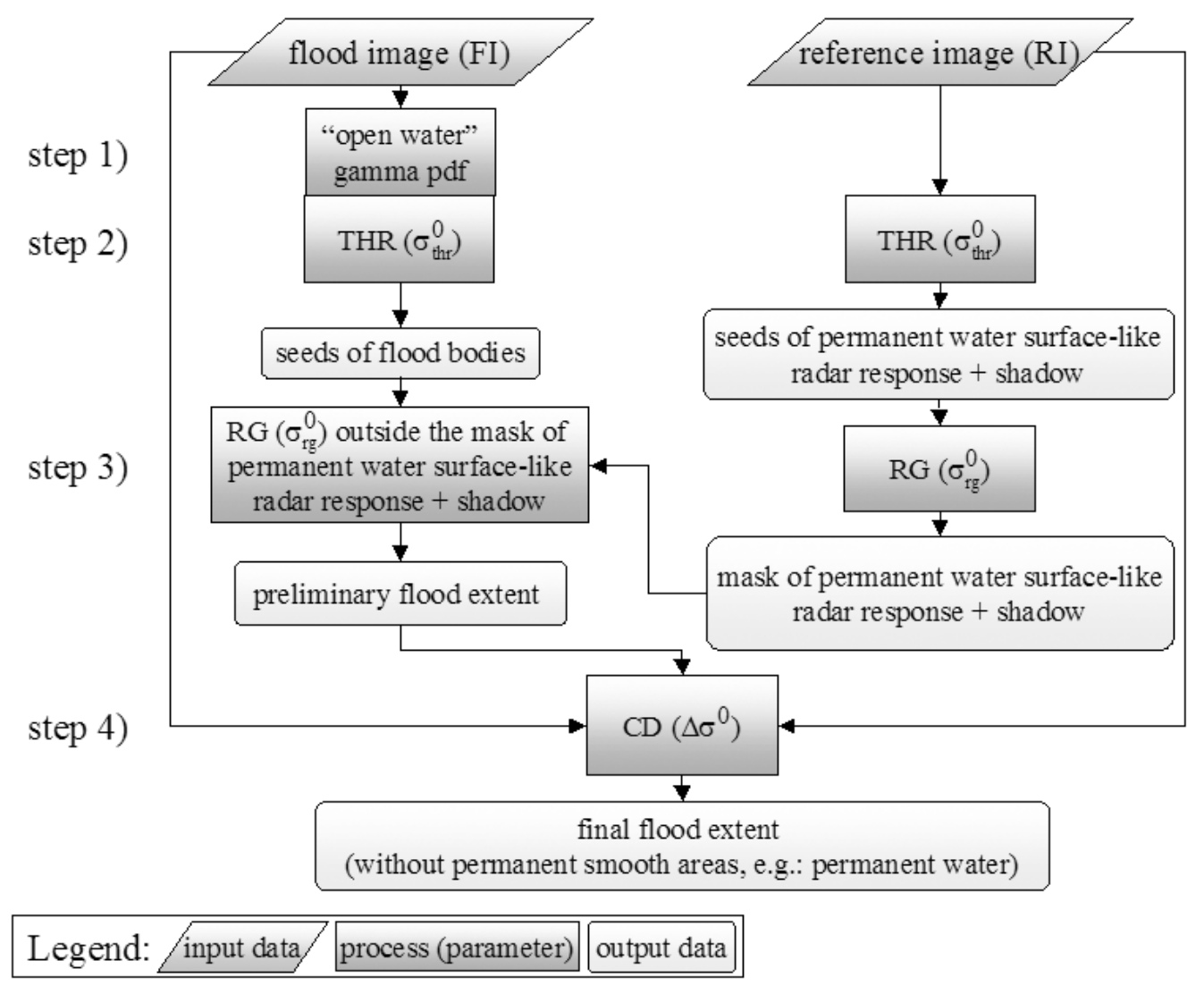




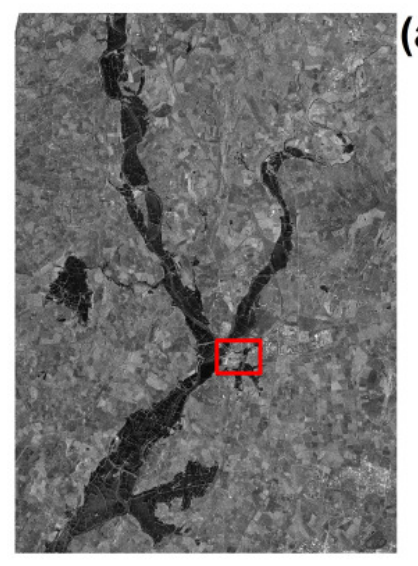

(a1)
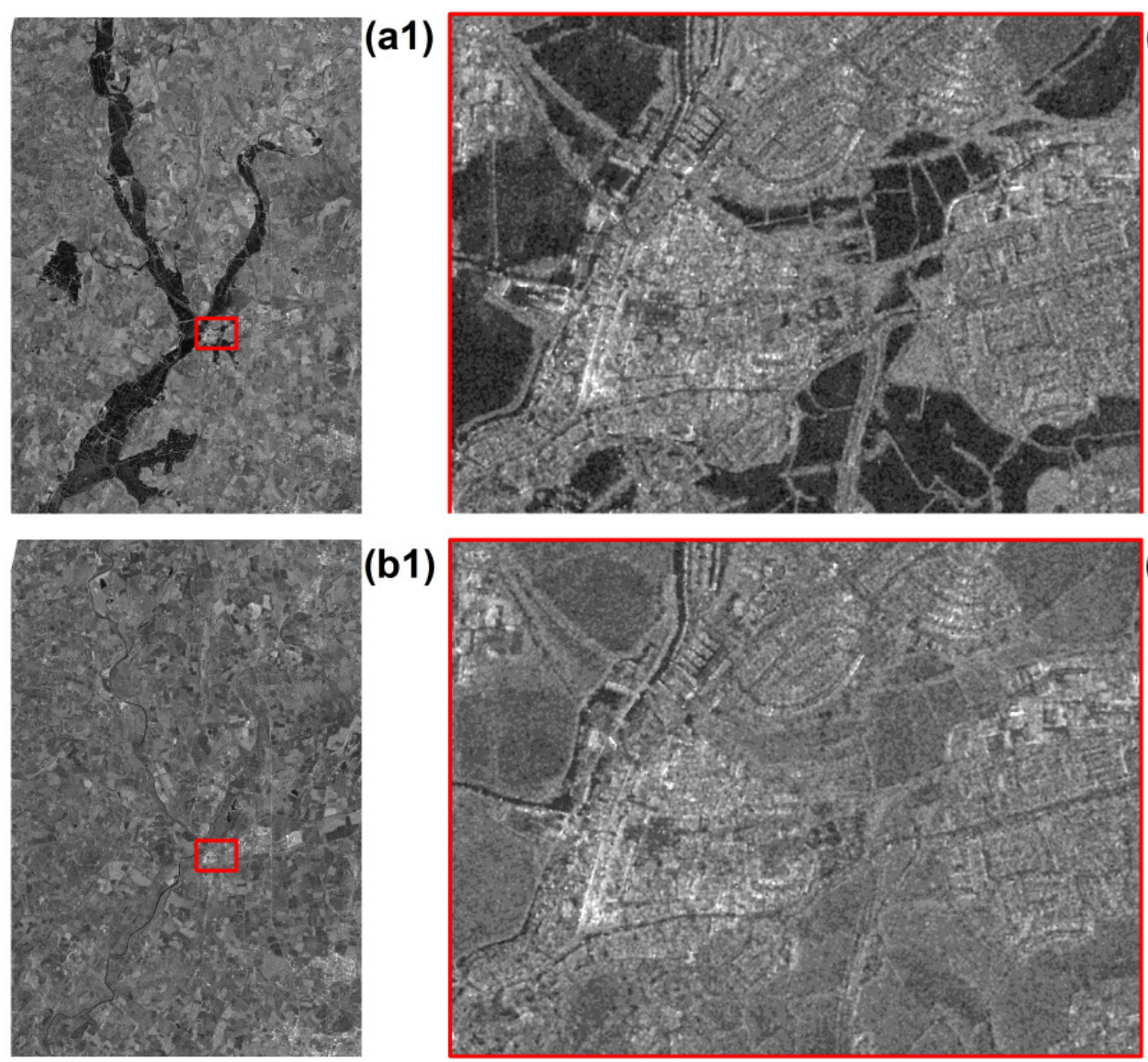

(b1)

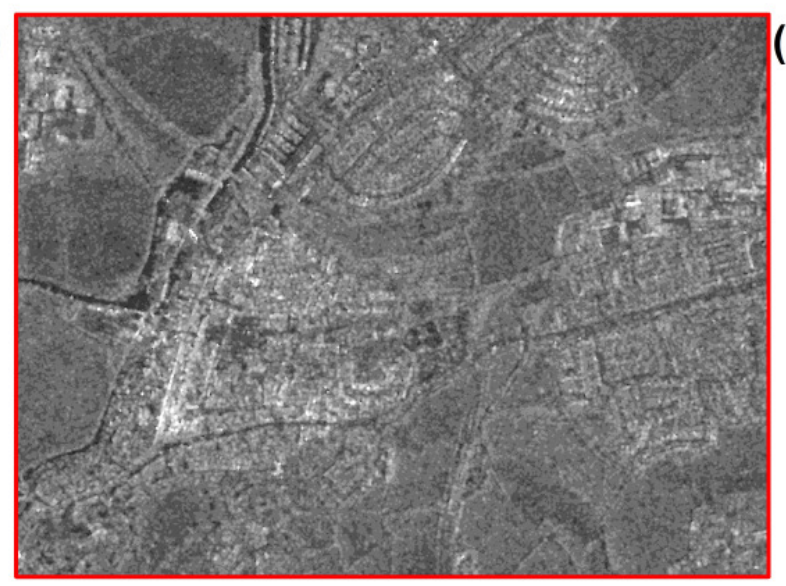

(b2) 


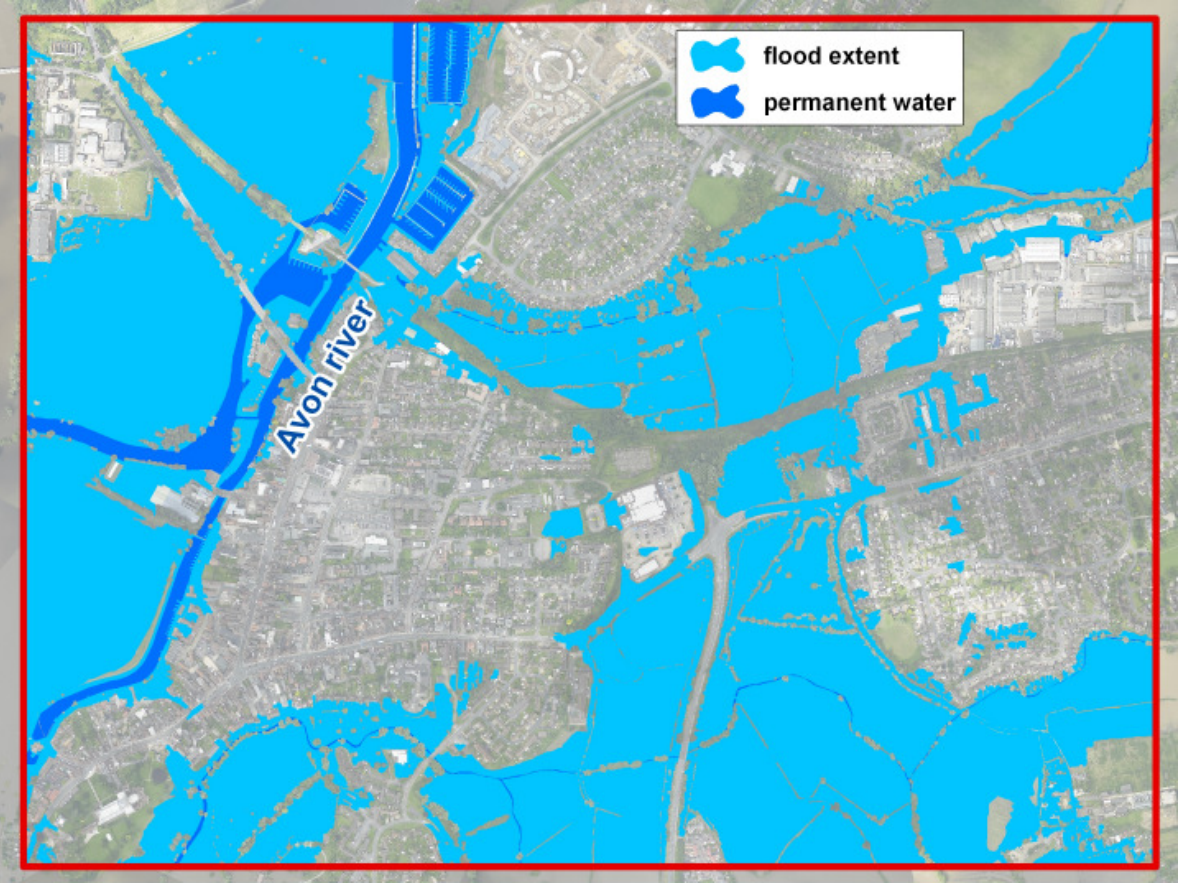

(a)

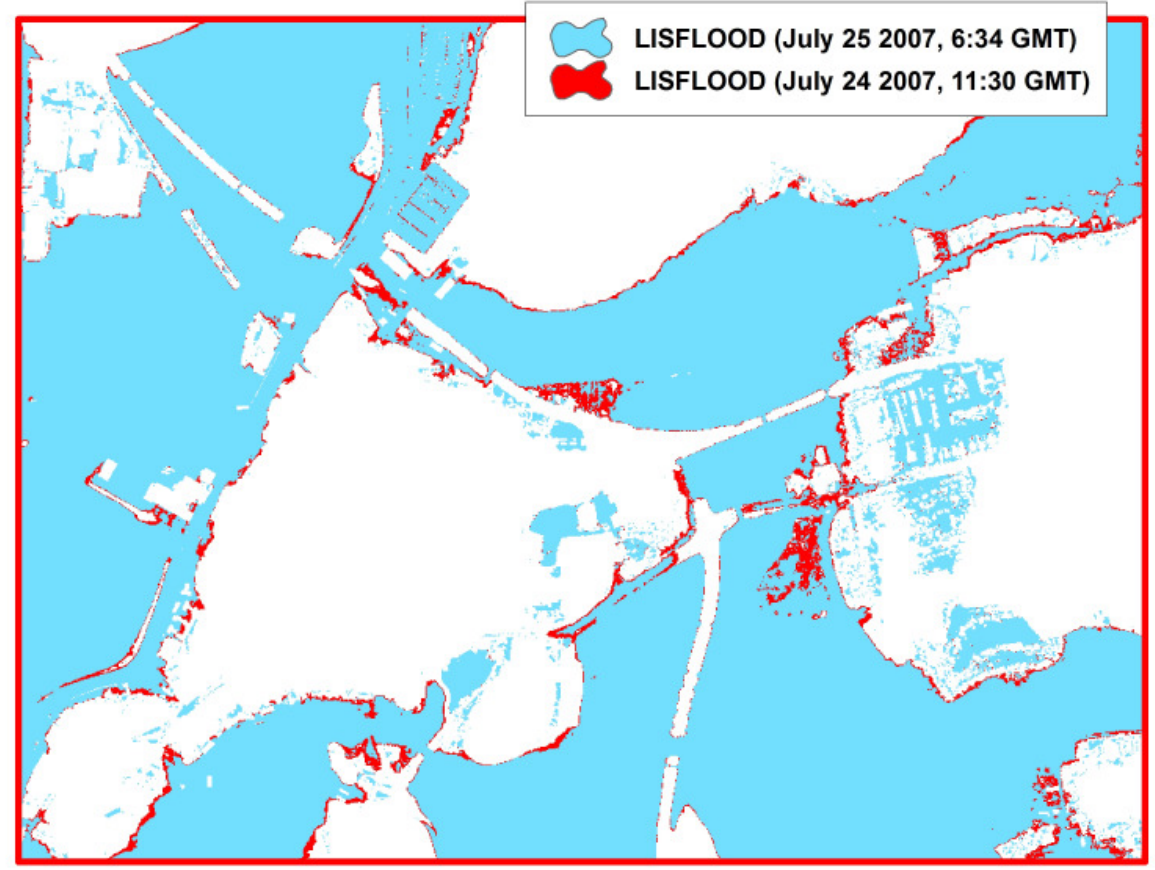

(b) 

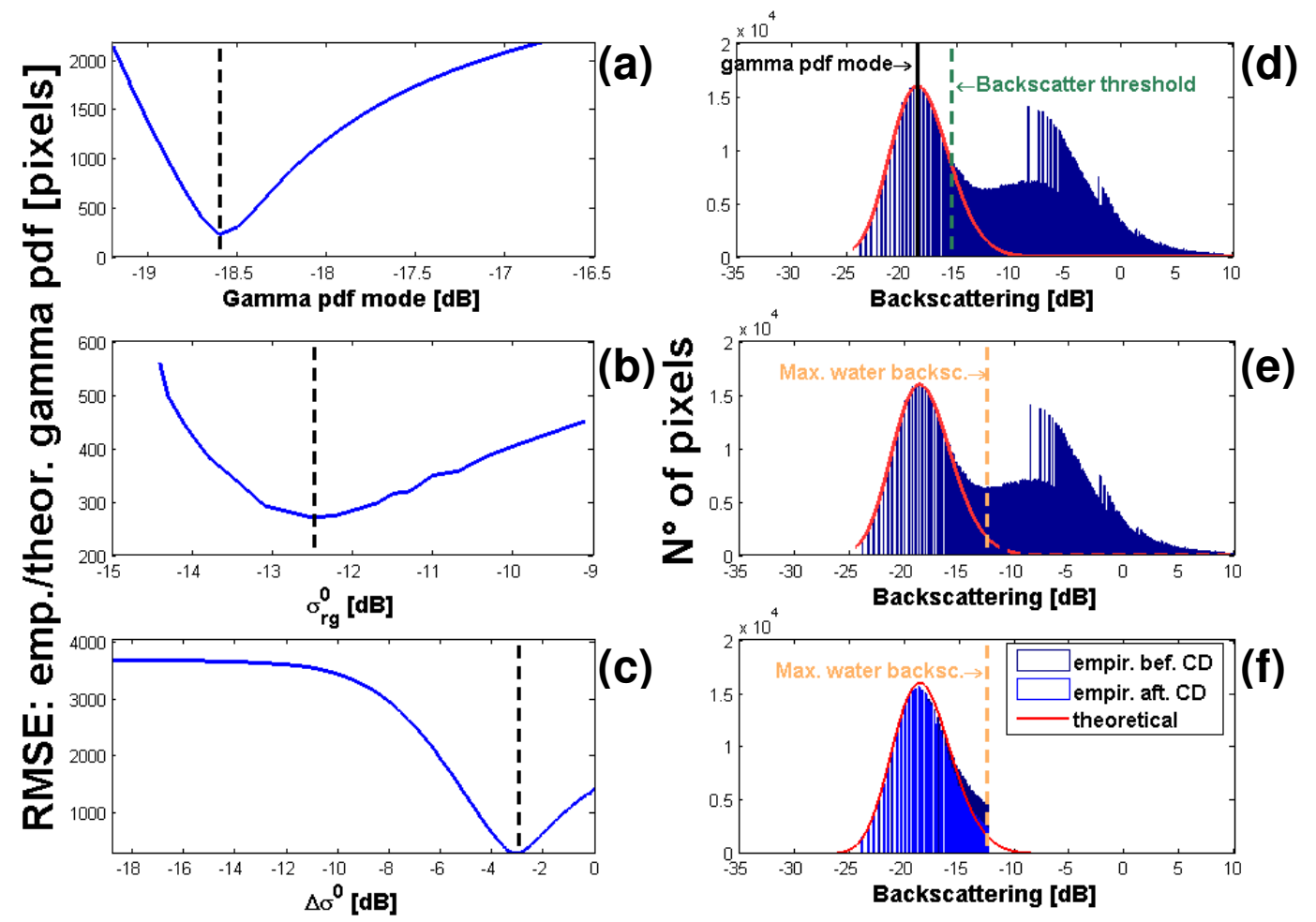


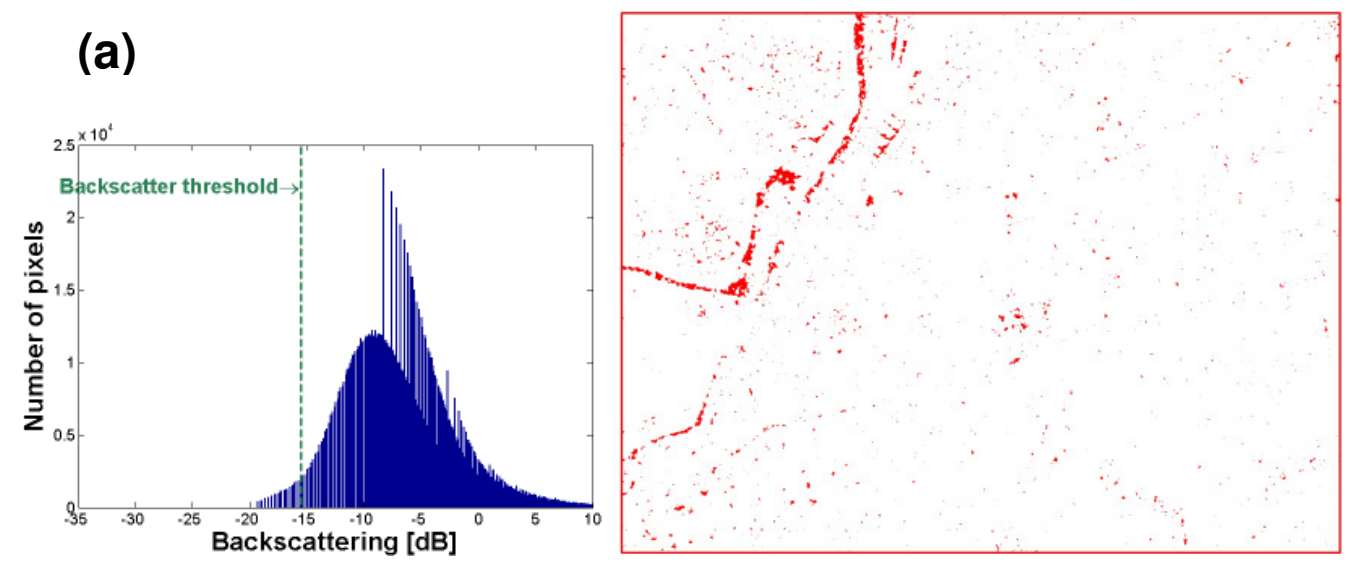

(b) 

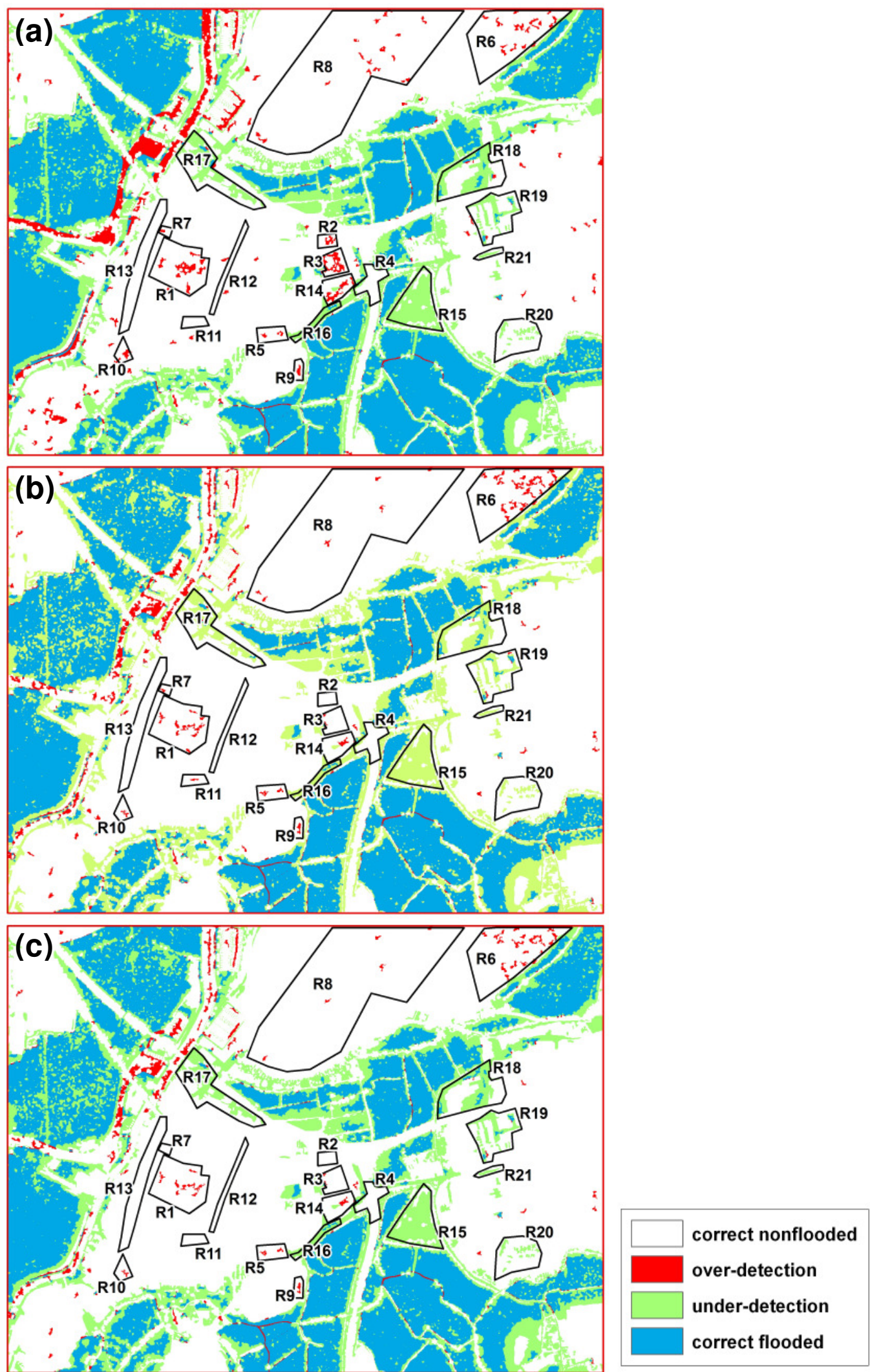


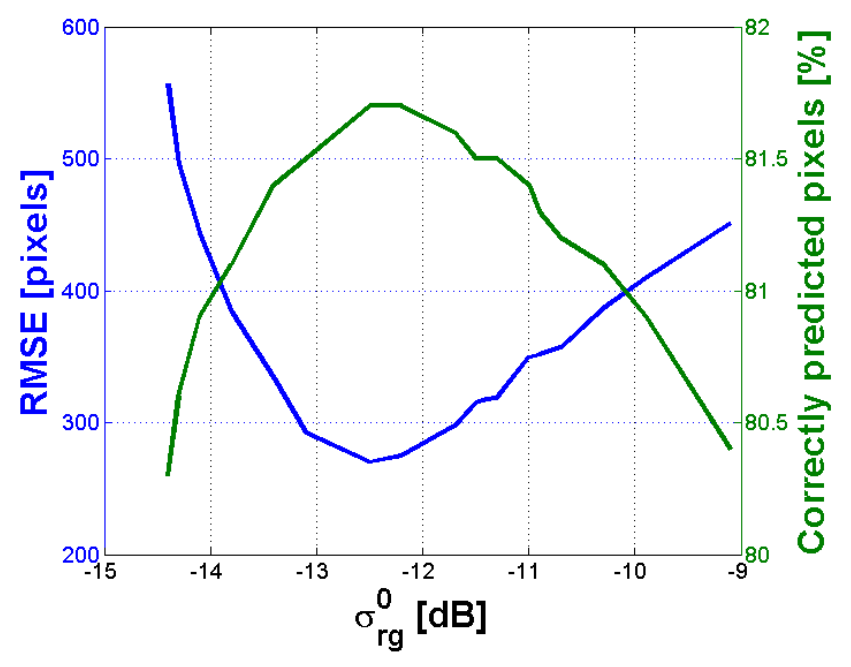



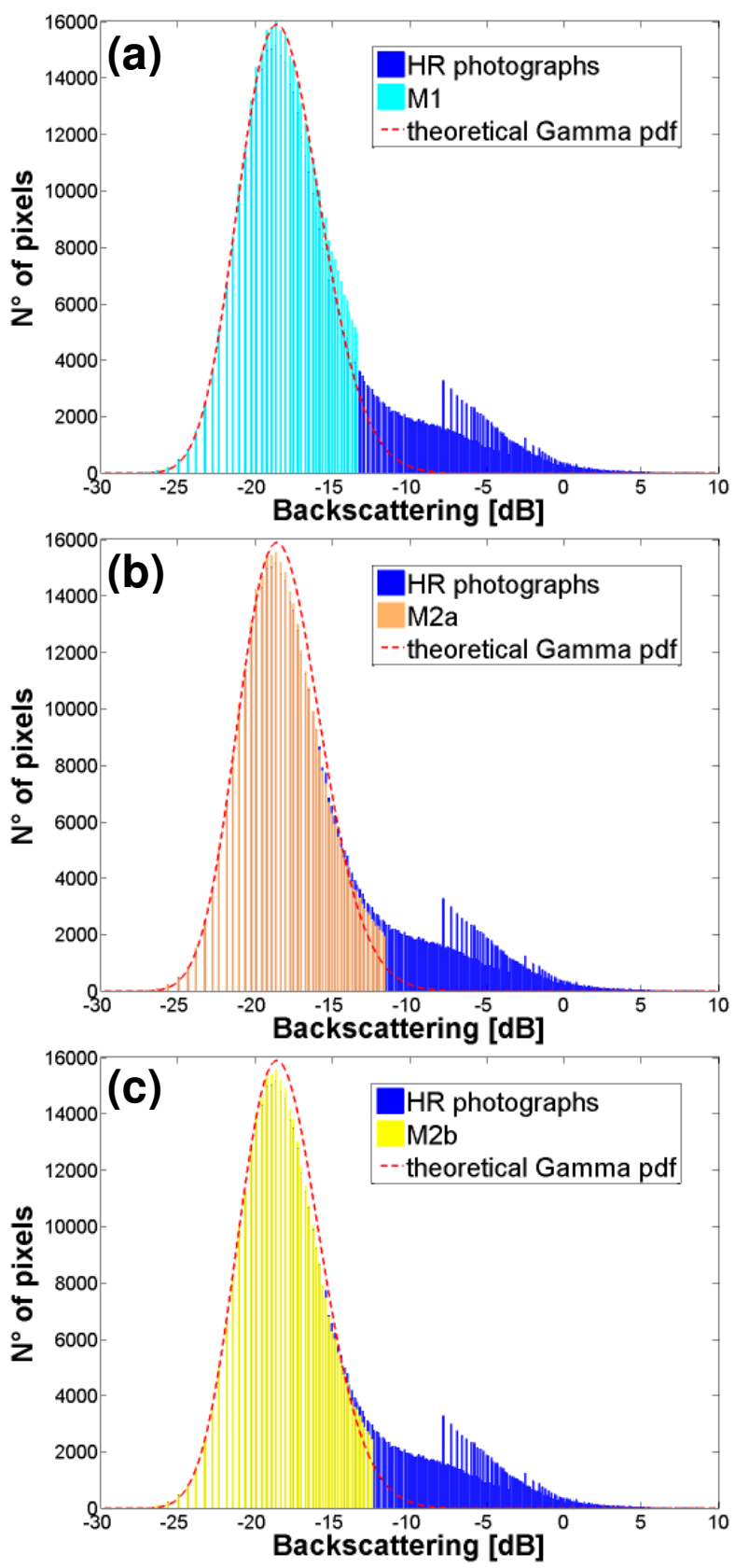

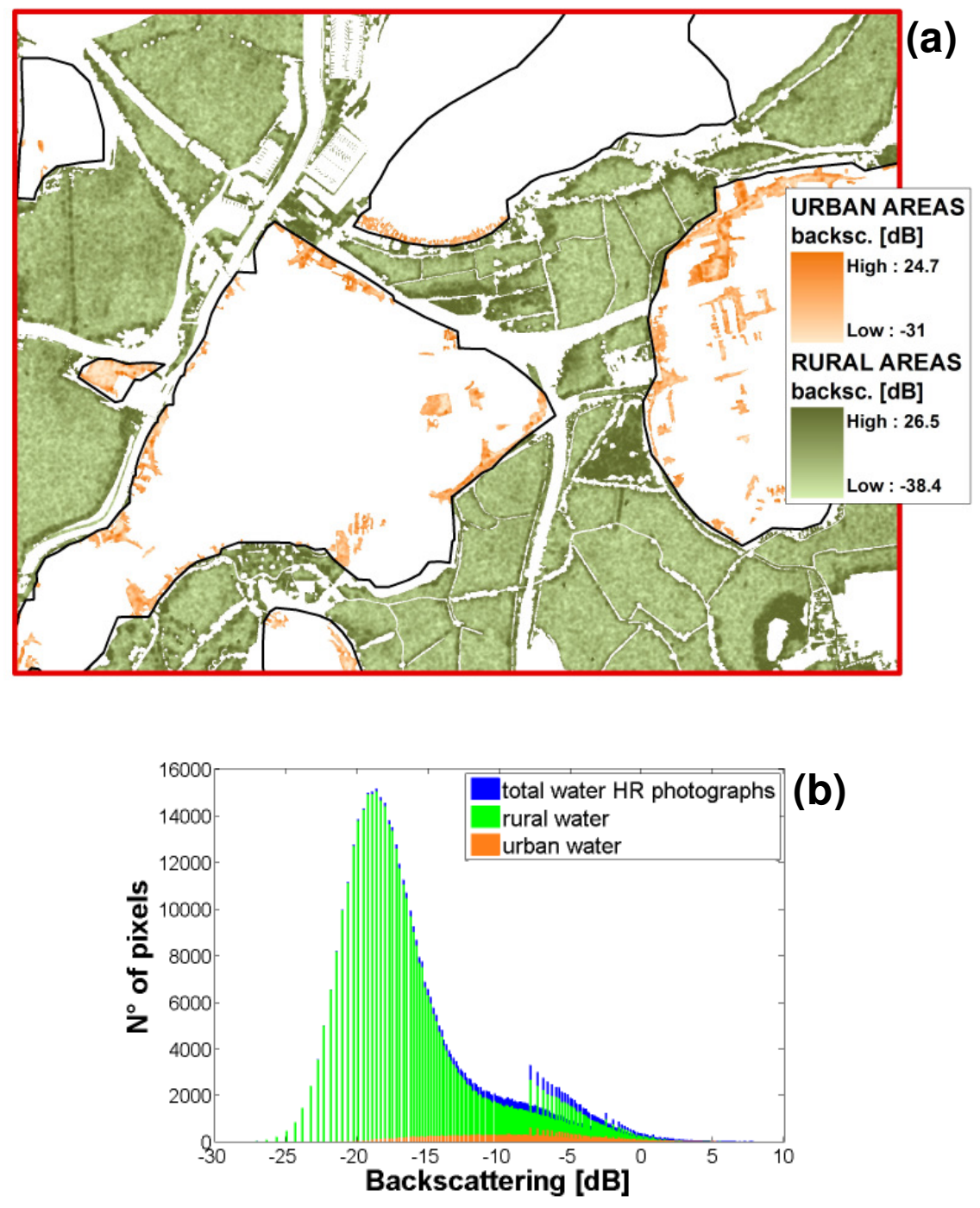

(b) 


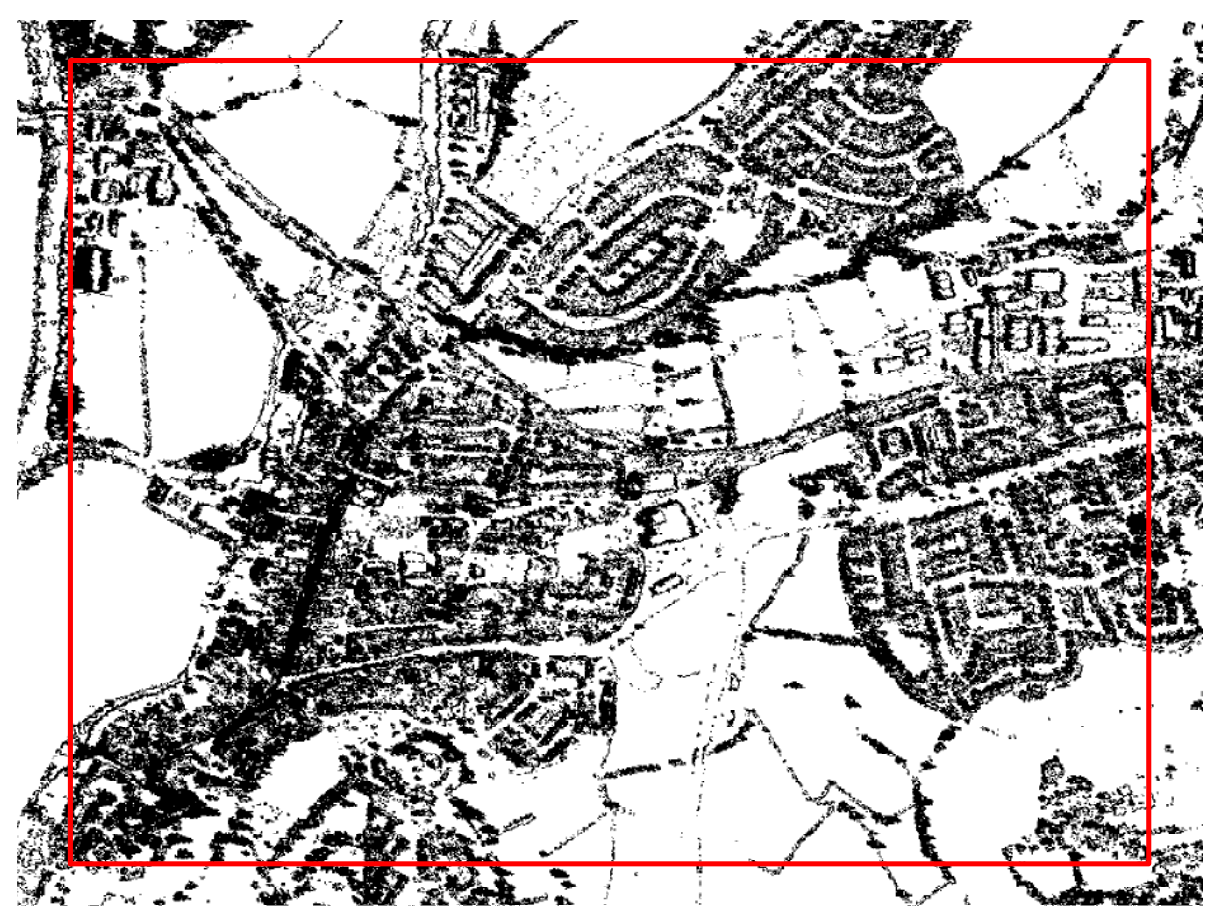

